\title{
ТЕОРЕТИЧЕСКИЕ ПОДХОДЫ К ЭКОНОМИЧЕСКОМУ СОДЕРЖАНИЮ И ФУНКЦИОНАЛЬНОЙ РОЛИ ГОСУДАРСТВЕННОГО СЕКТОРА В НАЦИОНАЛЬНОЙ ЭКОНОМИКЕ
}

\author{
(c) 2019 Ревкуц Александра Валерьевна \\ соискатель \\ Сибирский федеральный университет, Россия, Красноярск \\ E-mail:sebtk@mail.ru \\ (c) 2019 Демченко Светлана Капитоновна \\ профессор \\ Сибирский федеральный университет, Россия, Красноярск \\ E-mail: demchenko.svet@mail.ru \\ (c) 2019 Калюжнова Надежда Яковлевна \\ профессор \\ Иркутский государственный университет, Россия, Иркутск \\ E-mail:2010nyk@mail.ru
}

\author{
(c) 2019 Горев Владимир Петрович \\ профессор \\ Россия, Красноярск \\ E-mail: gorev_vladimir@mail.ru
}

Статья посвящена анализу теоретических подходов к экономическому содержанию и функциональной роли государственного сектора в национальной экономике. Представлены различия взглядов экономистов различных школ, обозначены основные задачи государственного сектора в современных условиях, отражены сложности определения его состава и границ.

Ключевые слова: государственный сектор, эволюция концепций, национальная экономика, сочетание частных и общественных интересов

Экономическое содержание и функциональная роль государственного сектора в национальной экономике представляет собой предмет научных дискуссий на протяжении всего существования экономической науки. Представители меркантилистской теории, в частности, У. Стаффорд, Т. Ман, А. Монкретьен, А. Серра и др. впервые акцентировали внимание на необходимости активного участия государственного сектора в национальной экономике, но связывали ее только со стимулированием экспорта и сдерживанием импорта для достижения страной активного торгового баланса.

Физиократы Ф. Кенэ, А. Тюрго, В. Мирабо, В. Дюпон де Немур, Г. Летрон выступали за идею «естественного порядка», за невмешательство государства в экономику, считали, что прирост продукта возможен только в земледелии. Классическая школа, в свою очередь, представлена трудами У. Петти, П. Буагильбера, А. Смита, Д. Рикардо, Дж. С. Милля.
$\mathrm{B}$ «Исследовании о природе и причинах богатства народов», опубликованном в 1776 году, А. Смит описал соответствующую экономическую роль государственного сектора и перечислил четыре функции правительственной деятельности по направлению расходов: обеспечение национальной обороны; установление отправления правосудия, которое предусматривает правопорядок в обществе, «а именно - защита, насколько это возможно, каждого члена общества от несправедливости и притеснения его другими членами общества, или обязанность установления точного отправления правосудия»; обязанность создавать общественные учреждения и необходимые общественные работы, которые частным фирмам не могут принести прибыль, но которые «необходимы для защиты общества и для отправления правосудия»; обязанность покрывать расходы, направленные на поддержку общественного развития [12].

Хотя Смит относится к представителям клас- 
сической школы, выступающей за минимальное вмешательство государства в экономику, его труды не указывают на значительную оппозицию государственному сектору в целях распределения в обществе.

В своем труде «Основы политической экономии» Джон Стюарт Милль утверждал, что путем реформ необходимо социально-экономические функции государства направить защиту интересов наименее защищенных слоев общества, на выравнивание доходов за счет государственного вмешательства через распределение налогов, на просвещение населения [9].

Сторонники марксистской теории выступают за безальтернативность преобразования частных, прежде всего крупных, предприятий в государственные, а рыночной экономики в целом - в плановую экономику. В такой экономической системе государственному сектору отводилась решающая роль по распределению ресурсов, организации производства и распределению благ, перераспределению доходов и ценообразованию в национальной экономике.

Неоклассики К. Менгер, Ф. Визер, О. БёмБаверк, У. Джевонс, Л. Вальрас, Дж.Б. Кларк, А. Маршалл, А. Пигу были сторонниками механизма свободной конкуренции, но тем не менее, некоторые из них отстаивали необходимость вмешательства государства в экономику. В частности, можно отметить Ф. Визера, обосновывающего необходимость планирования с целью обеспечения оптимального функционирования экономики, основываясь на принципах предельной полезности [6].

Л. Вальрас считал, что «проблеме производства и проблеме распределения общественного богатства не свойственен естественно научный характер, что воля человека свободна в своем проявлении, как в отношении производства, так и в отношении распределения общественного богатства. Однако как в плане собственности, так и в плане управления человечество всегда терпеливо продвигалось от исходного беспорядка фактов к конечному порядку принципов. Короче говоря, природа обеспечивает лишь возможность присвоения, а человечество совершает присвоение» [5].

А. Пигу, в свою очередь, считал, что свободный рынок приводит к конфликту частных и общественных интересов, следовательно, государственный сектор должен осуществлять контроль и регулирование, используя прямые (контроль за ценами и выпуском продукции в условиях монополии) и косвенные (использование налогов и субсидий) формы госрегулирования. В работе «Экономическая теория благосостояния» А. Пигу рассуждает по поводу выбора более предпочтительной формы государственного вмешательства в экономику - государственного контроля или государственного предпринимательства [10].

Необходимо отметить также представителей, так называемой Стокгольмской школы, К. Викселя и Э. Линдаля. В своих работах К. Виксель рассматривал вопросы роли и места государственного сектора экономики и был уверен необходимости государственного вмешательства в механизм равновесия. Э. Линдаль работал в направлении неравновесной динамической модели экономики, считал, что необходимо уменьшить степень неопределенности для достижения стабильности экономики, учитывая при планировании планов всех субъектов экономики - потребителей, фирм, государственного сектора [2]. По сути, их идеи предшествовали появлению кейнсианской теории.

В «Общей теории занятости, процента и денег» Дж.М. Кейнс обосновал необходимость государственного вмешательства в экономику, особенно в период экономических кризисов. По мнению Дж.М. Кейнса стимулирование совокупного спроса со стороны госсектора стимулирует мультипликационный эффект, занятость и рост дохода. В период кейнсианства произошло усиление позиций государственного сектора в экономике [8].

Дж. Робинсон в рамках посткейнсианства продолжила идеи Дж. М. Кейнса о том, что большинство рынков - это рынки несовершенной конкуренции, на таких рынках происходит рост цен, требующий активного вмешательства государства в экономику с использованием мер налогово-бюджетной политики [11].

Р. Буайе, являясь представителем теории регуляции, считает, что в основе взглядов регуляционистов находится «феномен влияния всего комплекса общественных отношений на экономические закономерности» [3]. В более поздних работах Р. Буайе отмечает, что эффективная координация на макроуровне предполагает наличие разделяемых ценностей и политического регулирования. «Одна из наиболее насущных исследовательских задач, стоящих перед институциональной политической экономией, заключается в нахождении критериев институ- 
циональных изменений - для того, чтобы идентифицировать те институциональные элементы, которые должны быть полностью сохранены, и те элементы, которые должны быть подвергнуты решительным изменениям» [4].

Представители институционального направления экономической мысли XX в. (Т. Веблен, Дж. Комонс, У. Митчел, Дж. Гэлбрейт и др.) обосновывают высокую экономическую роль государственного сектора вследствие необходимости общественного контроля над государственным регулированием национальной экономики и учета влияния на экономическое развитие имеющихся социальных отношений.

Если подвести итоги анализа взглядов экономистов различных школ о роли и месте государственного сектора в национальной экономике, то можно отметить следующее. Со времени появления идей А. Смита по экономическому содержанию и функциональной роли государственного сектора представители других школ возложили на государственный сектор задачи перераспределения доходов, проведения стабилизационной политики в период кризиса, обеспечения занятости и роста производства.

Необходимо отметить, что наиболее значимая роль при практической реализации экономической политики государственного сектора принадлежит перераспределению доходов. Распределение доходов представляет собой сложный механизм, зависящий от всего комплекса сложившихся социально-экономических отношений, отношений собственности, человеческого капитала, экономической политики государственного сектора.

Не всегда государственный сектор, используя механизм перераспределения доходов за счет налоговой системы и трансфертов, может обеспечить приемлемый обществом уровень социально-экономического неравенства. И практически спорным остается вопрос, какой уровень дифференциации доходов является оптимальным, чтобы не уменьшались стимулы к предпринимательской активности, и не росло недовольство незащищенных групп населения.

При этом задачи, которые призван выполнять государственный сектор в современной экономике, следующие:

- обеспечение правовых основ функционирования экономики, конституционных прав и свобод населения;

- содействие достижению страной социально-экономической стабильности и высокой эффективности национальной экономики;

- обеспечение надлежащего уровня национальной безопасности страны;

- регулирование внешних эффектов и «достойных нужд»;

- стимулирование научно-технического прогресса;

- социально-экономическое программирование и планирование основных параметров развития национальной экономики.

Мировой опыт неопровержимо доказывает рост роли государственного сектора в период преодоления последствий «великой депрессии», в послевоенные годы, включая 60-70-е годы, когда в экономической политике западных стран реализовывалась кейнсианская концепция стимулирования государственным сектором совокупного спроса, заложившая основы современной экономической системы стран 3апада [8].

На протяжении всей истории изучения экономики возникали различные концепции и школы, каждая из которых имела своё представление о том, каковы роль и место государства в экономике.

Следует обратить внимание на то, что представители всех неоклассических школ защищают принципы саморегулирования рынка, следовательно, необходимость ограниченного государственного регулирования экономики, которое должно концентрироваться на защите конкуренции, обеспечении определенных социальных гарантий. При этом выявленные существенные различия в определении экономической роли государственного сектора представителями различных школ можно объяснить изменениями реальных условий хозяйствования, которые влияли на формирование научных концепций исследователей определенной исторической эпохи. Поэтому невозможно использовать «в чистом виде» концепции одной из рассмотренных теорий в условиях трансформации государственного сектора России.

По нашему мнению, экономическое содержание и функциональная роль государственного сектора в национальной экономике должны оцениваться со следующих позиций:

1. Главная задача системных преобразований - формирование условий для социальноориентированной рыночной экономики 
(институционального, инфраструктурного, законодательного обеспечения системных преобразований).

2. Обеспечение экономических и социальных условий для обеспечения конкурентных преимуществ национальной экономики.

3. Укрепление состояния внутреннего рынка страны и реализация инновационной модели развития национальной экономики за счет реализация конкурентных преимуществ.

4. Переосмысление логики макроэкономической стабилизации (использование не только монетарного, но и кейнсианского, институционального и воспроизводственного подходов для стабилизации национальной экономики).

5. Необходимость повышения эффективности функционирования государственного сектора, которая связана с существенным усилением его влияния на развитие социальной сферы [1].

Рассматривая содержание государственного сектора, на наш взгляд, нельзя оставить без внимания вопрос состава и определения его границ. Это необходимо, прежде всего, для того, чтобы иметь возможность количественной оценки масштабов государственного сектора. В России к предприятиям государственного сектора, как и в большинстве развитых стран, относят организации, которые владеют не меньше чем 50\% капитала предприятия, которые могут контролировать его цели и функции. Это закреплено в постановлении Правительства РФ № 1 от 04.01.1999 г., и перечислены они следующим образом: государственные учреждения, государственные унитарные предприятия, акционерные общества, в уставном капитале которых больше 50\% акций находится в собственности государства. Официально закрепленного перечня таких предприятий в России нет. Но есть, например, во Франции, там ежегодно обновляется официальный перечень государственных предприятий, в состав которого включаются юридические лица с долей участия более $30 \%$ и все филиалы национальных предприятий. В России ни одна из форм собственности не охватывает в полной мере понятие государственного сектора. Понятия государственной собственности и государственного сектора при статистическом учете значительно разняться. Это возникает из-за дублирования статуса территории таких городов, как Москва, Санкт-Петербург, Севастополь, так как они имеют статус субъектов федераций и также имеют муниципальную систему управле- ния, в связи с чем, возникают проблемы с корректным учетом статистических данных. Наличие у государственных предприятий «золотой акции» в России фактически носит «удерживающий» характер, обеспечивая только сохранение собственности приватизированных компаний, в то время как во многих европейских странах наличие такой «золотой акции» у государства дает ему право управлять производственными аспектами деятельности предприятия и влиять на формирование производственных программ. Состав государственного сектора в России закреплен законодательно, но все равно имеет определенные пробелы, которые значительно сказываются при анализе статистических данных и, следовательно, на представлении о его масштабе. Еще одним элементом, искажающим представления о размерах государственного сектора, является сектор теневой экономики, которую называют скрытой или неформальной экономикой. Теневой сектор экономики состоит из скрытого производства, запрещенной деятельности, способной приносить доход, а также экономической деятельности, не учитываемой официальной статистикой. Теневая экономика включает в себя все нелегальные и неучтенные виды экономической деятельности.

Обобщая вышесказанное, рассмотрев различные походы к экономическому содержанию и функциональной роли государственного сектора, не стоит забывать об изменениях в самом обществе. В отличие от модели социальной организации, характерной для периода начала формирования рыночных основ, в наше время присутствуют не только наиболее сложные модели хозяйствования, но и есть фактически отсутствующий ранее социальный сектор экономики. Современное государство сегодня имеет гораздо больший сектор социальных задач, ориентированных на современные тенденции общества. Современное государство находится под мощным воздействием научно-технического прогресса, всемирной интеграции экономики разных стран, информатизации и, соответственно, ориентировано на решение глобальных проблем мировой экономики, таких как терроризм, политические войны и т.д. Эти обстоятельства совместно со многими иными факторами являются причиной кардинального изменения места и роли государства в национальной экономике в условиях современного общества. 


\section{Библиографический список}

1. Александров Ю.Л., Суслова Ю.Ю., Демченко С. К., Мельникова Т. А., Демченко О. С. Проблемы эффективности и устойчивости развития макроэкономической системы: монография. Красноярск: Сибирский федеральный университет, 2015. 163 с.

2. Блауг М. Экономическая мысль в ретроспективе. М.: Дело Лтд, 1994. 720 с.

3. Буайе Р. Теория регуляции: Крит. анализ. М.: Рос. гос. гуманит. ун-т, 1997. 212 с.

4. Буайе Р., Бруссо Э., Кайе А., Фавро О. К созданию институциональной политической экономии // Экономическая социология. 2008. Т. 9. № 3. С. 17-24.

5. Вальрас Л. Элементы чистой политической экономии. М.: Изограф, 2000. 448 с.

6. Визер Ф. Теория общественного хозяйства: https//www.libertarium.ru (дата обращения: 30.08.2019).

7. Волошин А.В., Демченко С.К., Суслова Ю.Ю., Калюжнова Н.Я., Каячев Г.Ф. Обзор моделей эволюционного развития социально-экономических систем // Экономика и предпринимательство. 2019. № 7 (108). С. 202205.

8. Демченко С.К. Теории экономического роста во взаимосвязи с концепцией мультипликатора // Проблемы современной экономики. 2006. № 1-2 (17-18). С. 85-89.

9. Милль Дж. Ст. Основы политической экономии. Т. 1-3. 498 с.

10. Пигу А. Экономическая теория благосостояния. Т. 1. М.: Прогресс, 1985. 512 с.

11. Робинсон Дж. Экономическая теория несовершенной конкуренции. М.: Прогресс, 1986. 471 с.

12. Смит А. Исследование о природе и причинах богатства народов. Книга V.М.: ЭКСМО, 2007. 960 с. 